\title{
A NEW CHAPTER IN INNOVATION
}

A growing appreciation that cooperation and competition can coexist is transforming the life-sciences innovation landscape. Development was once shrouded in secrecy, but now organizations are coming together. By David Holmes; illustration by Mohamed Ashour.

\section{STRAIGHT PATHS OF OLD}

Historically, life-sciences partnerships were linear and closed in nature. The delivery of therapies was handled separately - the ending as that of another began.

This arrangement had its advantages. Risk and reward increased as the drug moved of dialogue with the wider community could often result in costly duplications of effort.

\section{USS2.6 billion}

Average pre-tax cost per approved drug, including cost of failures ${ }^{1}$ conception, development and involvement of one partner down the chain. But the lack

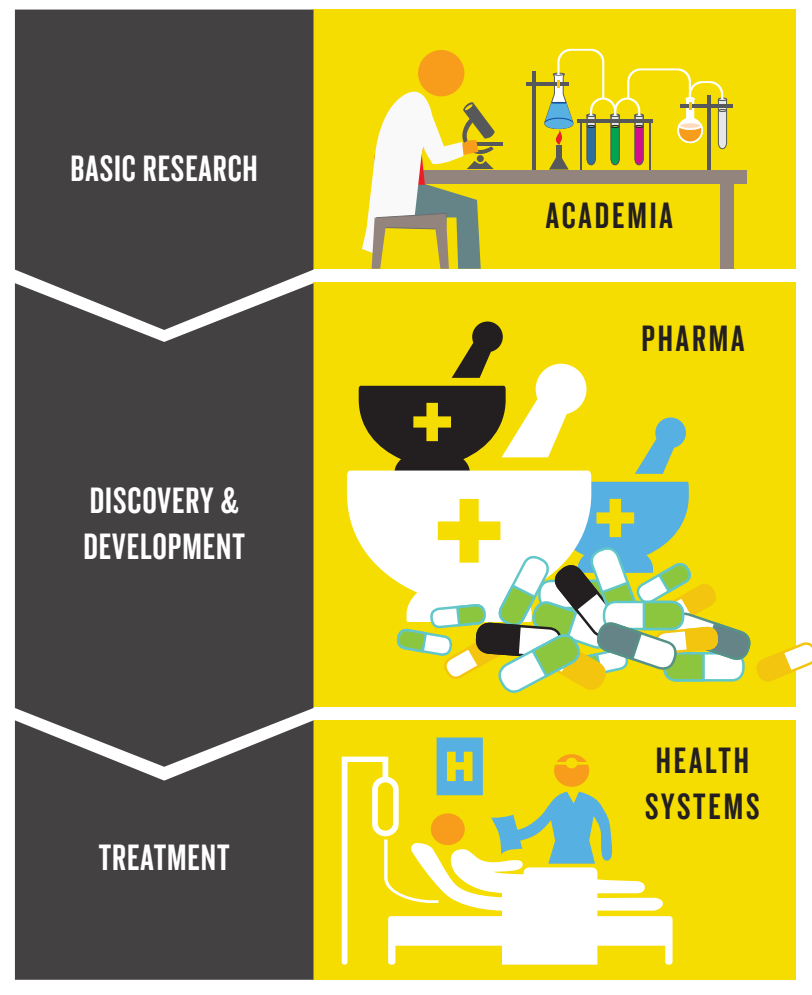

\section{MOORE PROBLEMS}

The number of drugs approved by the US Food and Drug Administration (FDA) per billion US dollars spent on research and development (R\&D) has halved roughly every 9 years since 1950 - seemingly the opposite of Moore's law (Gordon Moore, co-founder of technology company Intel, observed that the number of transistors that can be placed, inexpensively, on an integrated circuit doubles every 18-24 months) $)^{2}$. In an effort to defy 'Eroom's law', organizations have been forced to search for ways to boost returns on investment.

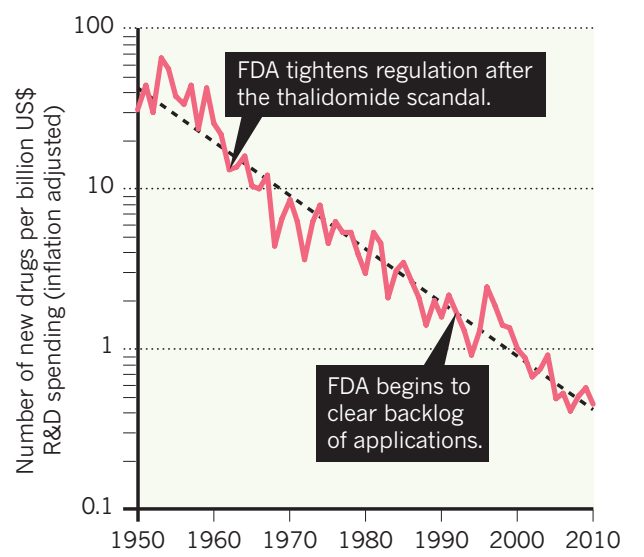

\section{SQUEEZED MARGINS}

Increasing R\&D costs and competition from drugs that are no longer covered by patents have squeezed the margins of the conventional linear innovation model.

\section{INCREASING INFORMATION}

As researchers better understand the biological complexity of targeted diseases, and the technological complexity of drug discovery and the size of data sets increase, organizations are becoming more reliant on outside expertise.

\section{UNMET NEEDS}

A conventional closed model of innovation is unsuitable for some medical needs, such as the development of antimalarials or Ebola vaccines.

\section{A GROWING MOVEMENT}

In response to the limitations of the closed model of innovation, a growing number of organizations have come together over the past two decades to share ideas, data and tools with each other, and often with the wider community.

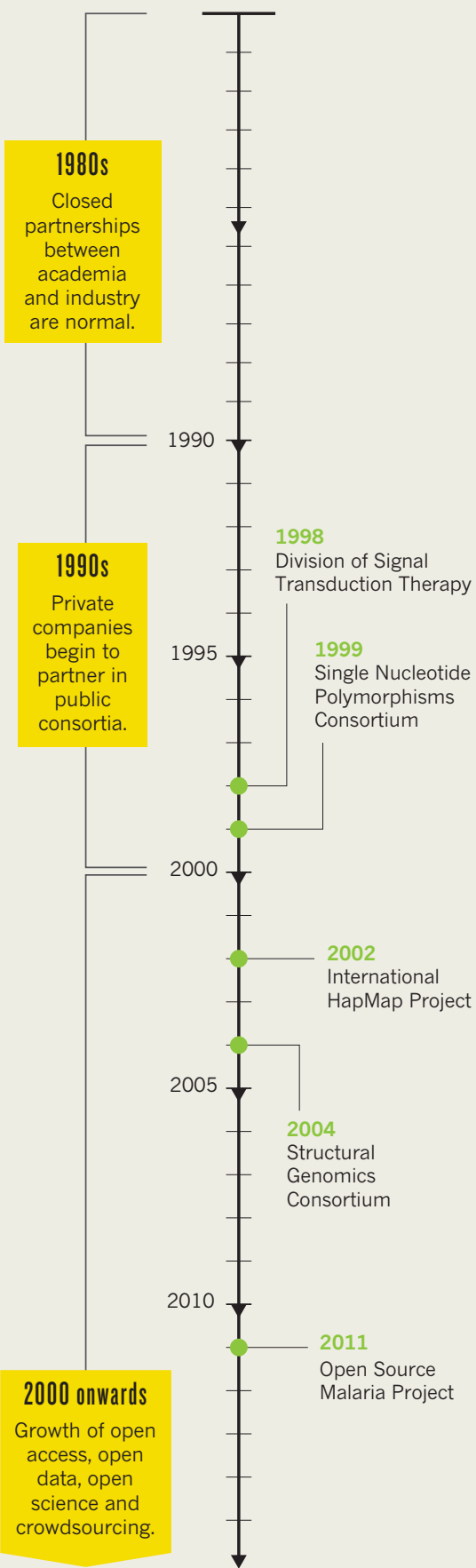




\section{OPEN TO INTERPRETATION}

According to Google's Ngram Viewer, which shows the relative frequency with which certain words and phrases are published, the phrase 'open innovation' gained prominence in the English language in 2003 - the year that business specialist Henry Chesbrough, now at the University of California, Berkeley, used it to describe the concept that companies should use external ideas as well as internal ones to advance their technology. But open innovation is just one of the terms that seeks to capture different, but overlapping, themes of openness in the broader innovation ecosystem.

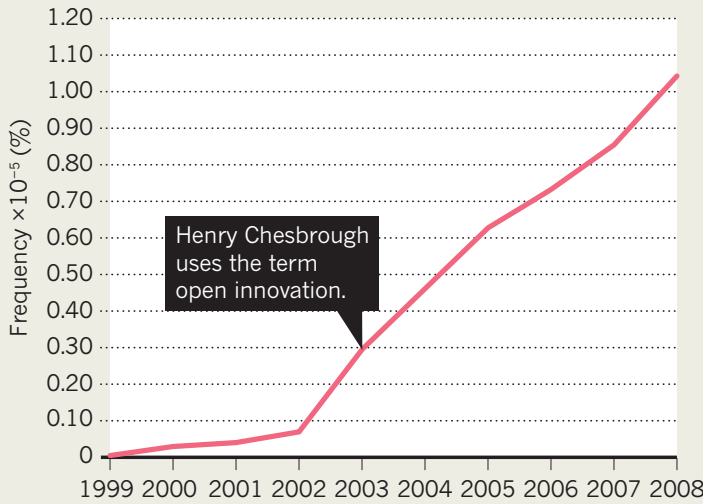

\section{OPEN SOURCE}

Pioneered by the software-development industry, open-source projects make the fruits of open collaboration free to everyone, with little or no direct profit for the collaborators.

\section{OPEN ACGESS}

Open access was a major shake up to the conventional publishing model. Literature is digital, online, free at the point of use and usually free to reproduce in some form.

\section{DPEN DATA}

The Open Data Institute in London describes open data as data that anyone can access, use and share.

\section{DPEN SEIENGE}

Open science is the practice of science such that others can contribute. Lab notes are freely available, and the research and its underlying methods can be shared.

\section{DEGREES OF OPENNESS}

CASE STUDIES

Whether or not a collaboration qualifies as an example of open innovation can be subjective, but criteria (pictured) ${ }^{3}$ devised by the Wellcome Trust in London can be used to categorize collaborations. It is generally agreed that the ideal open initiative would be a broad collaboration with public participation through all stages of innovative development, resulting in an output that is free to all.
Whom a collaboration is open to can vary, from an internal collaboration within an organization to a project fully open to anyone.

\section{PARTICIPATION}

\section{Open to the public}

International collaborations with multiple partner types

Multiple partner types in a similar geography or limited number of international partners

Limited number of partners $(<10)$ within a similar geography

2

Internal collaboration within a single organization

3

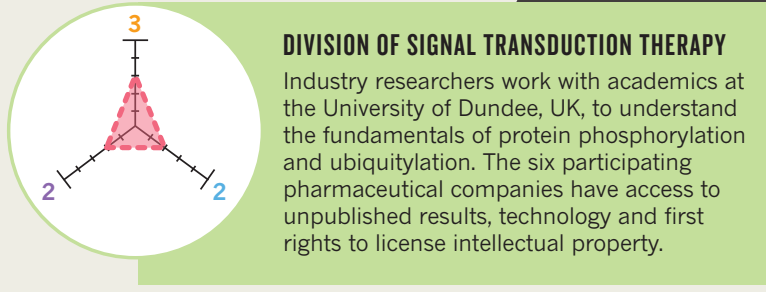

\section{OPEN SOURCE MALARIA}

The project takes promising public domain compounds and refines them for clinical trials. Anyone can contribute and all experimental data are shared in near-real time. E-mails are discouraged, with contributors instead urged to communicate on public discussion boards.

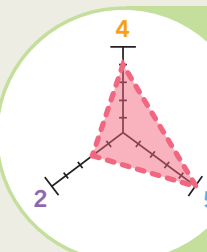

STRUCTURAL GENOMICS CONSORTIUM

The consortium is a public-private partnership that aims to catalyse drug-discovery efforts by determining the structure of potential drug targets. The structures are then released to the public, but no data are made available before then.

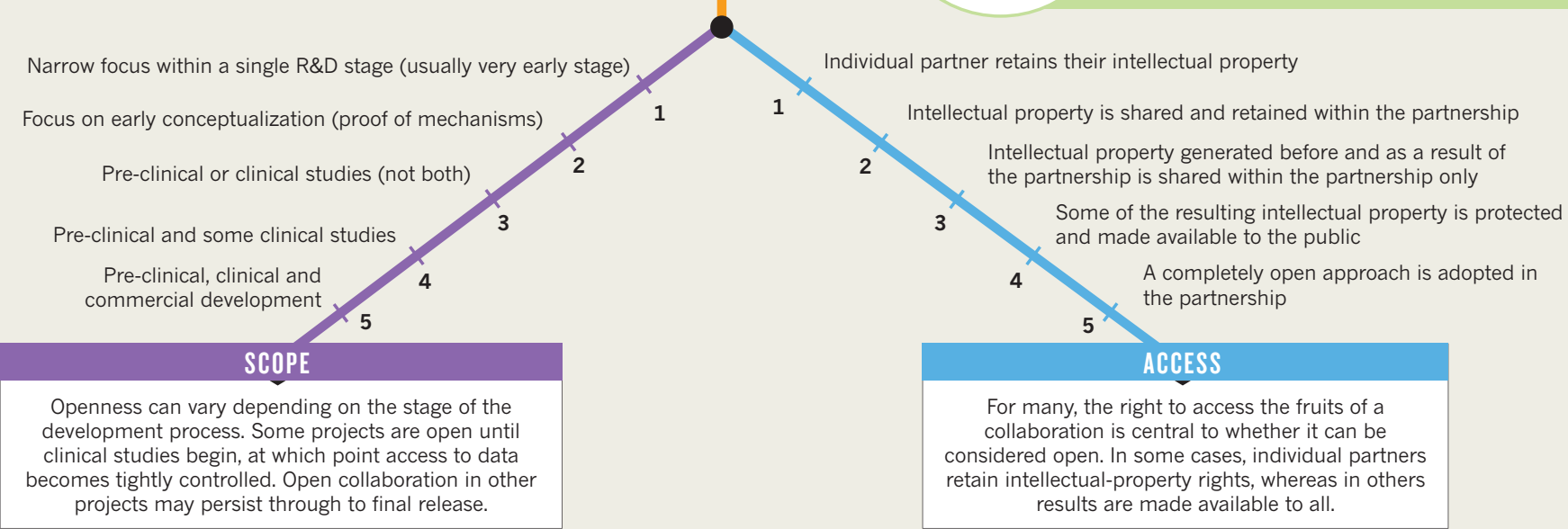

